\title{
Incorporation of Terrestrial Invertebrate Data in Mine Closure Completion Criteria Adds Sensitivity and Value
}

\author{
J.D. Majer Department of Environmental Biology, Curtin University of Technology, Australia \\ G. Orabi Department of Environmental Biology, Curtin University of Technology, Australia
}

L. Bisevac Department of Environmental Biology, Curtin University of Technology, Australia

\section{BACKGROUND}

Inspection of the few documented criteria for evaluating whether rehabilitated minesites have reached a stage where bond-release can occur, or where responsibility for the land can be relinquished, reveals a largely generic approach. Criteria include site safety, soil stability, and aesthetic issues. The biological criteria tend to be extremely generic in their approach, and include plant cover, plant density, plus a range of surrogate indicators of animal habitat, such as the existence of coarse woody debris. Although a range of habitat factors may be present, there are often no data to indicate whether the previous occupants have returned, or whether the ecosystem is functioning in a self-sustaining way. When fauna are included, the focus is generally on the vertebrates, as these are the groups that engender public interest and concern. Invertebrates tend to be omitted from the agenda, even though they play a vital role in ecosystem functioning. This paper presents a case for including invertebrates in the list of mine closure Completion Criteria. It does so on the premise that invertebrates comprise the bulk of animal biomass and most of its biodiversity, and also because of their role in processes such as pedogenesis, nutrient cycling, pollination, etc. Two studies which 'roadtest' the efficacy and cost-effectiveness of various invertebrate groups as indicators of rehabilitation success are presented, one on the Iluka sand mines at Eneabba, WA, and the other on the Worsley Alumina bauxite mines, near Boddington, WA. In both cases, groups such as ants, beetles, spiders and hemipterans provide insightful data on the way in which the ecosystem is recovering. The degree to which these groups track ecosystem recovery often exceeds that of the vertebrates. Furthermore, the cost of surveying certain groups of invertebrates is far more economical in terms of expense and data-yield than that which is involved in surveying vertebrates. The former does require specialised expertise and equipment. However, such expertise is now becoming available in the consulting industry and the necessary equipment is inexpensive, so this should not be seen as an impediment. In view of the resources required to carry out this work, and also of the need to provide rapid assessments of closure success in various minesites, it is recommended that invertebrates be used in a subset of the mined areas, using representative areas of mature rehabilitation.

\section{INTRODUCTION}

A commonly accepted goal of rehabilitation of mined land is to restore the structure, diversity, function and dynamics of the disturbed ecosystem. In the past, the technology required to meet these goals has been derived from experience, although research over the past four decades into rehabilitation technologies has resulted in considerable advances in such procedures. The need to carry out high-quality rehabilitation has become more acute in the industry with the phasing in of Performance Standards for assessing ongoing rehabilitation, and Completion Criteria for assessing the end product (Mills et al., 1992). In some cases, bonds are payable that are not returned until adequate rehabilitation, which meets prescribed Completion Criteria, has been demonstrated. In Western Australia, Completion Criteria are not formally nominated, but appear in various conditions of project approval under three classes of controlling acts, namely: the Environmental Protection Act - EPA (1986); the Mining Act (1978) and various agreement acts which pertain to the project being developed (Mills et al., 1992). The EPA has now produced a draft guidance statement on rehabilitation of terrestrial ecosystems (EPA, 2006).

Completion Criteria are defined as rehabilitation performance objectives (Tacey and Treloar, 1994). Because of the wide range of possible final land uses and of variation in soil conditions and climate, there are no general standards for creating such objectives (Waggitt and McQuade, 1994). The indicators, therefore, are 
site-specific, and include physical and biological factors, as well as water quality and safety measures. Such indicators should allow Government and other agencies, as well as mining companies, to evaluate the quality of rehabilitation techniques employed and to evaluate the success of the rehabilitation in reaching a selfsustaining ecosystem that is suitable for the agreed final land use. The time required for a newly created ecosystem to be considered self-sustaining varies greatly. Some Australian States do not have monitoring programmes after mining close-out, while others require mining regulators to continue monitoring; e.g., in NSW up to 20 years, in Queensland 12-14 years and in WA 5-10 years (Waggitt and McQuade, 1994).

Invertebrates play a pivotal role in ecosystems, both natural and disturbed (Wilson, 1987; Majer, 1989; Erwin, 1991). Yet, to our knowledge, none of the established Completion Criteria schedules require the reestablishment of adequate invertebrate communities to be taken into account, a fact that is reflected in the preamble to the Western Australian EPA draft guidance statement mentioned earlier (EPA, 2006) This weakness in the system may partly result from the authorities not fully recognising the importance of invertebrates in ecosystem functioning. This is unfortunate, since invertebrates probably play a major role in the success of rehabilitation, facilitating soil aeration and drainage (Abbott, 1989), litter decomposition and nutrient cycling (Ward et al., 1991; Hutson, 1989), pollination (Faegri and van der Pij1, 1971), seed dispersal (Majer, 1990) and herbivory (Whelan and Main, 1979), as well as providing a source of food for vertebrate predators (Figure 1). It follows from this that the colonization of an abundant and diverse fauna of a particular taxonomic group should be indicative of the effective operation of the ecosystem functions that the group is associated with.

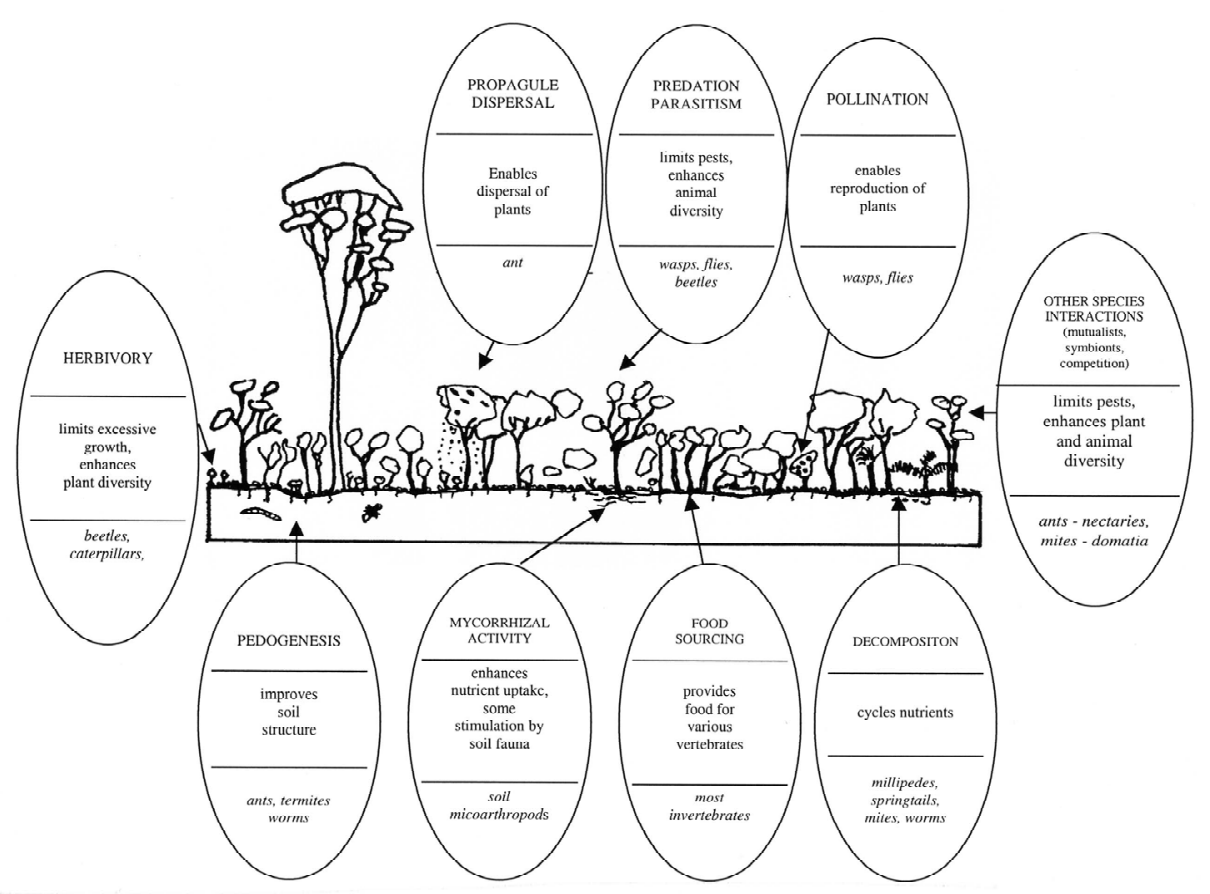

Figure 1 Ecosystem functions and processes that need to be established in rehabilitated land. Note that invertebrates are key players in most interactions

\subsection{Aims of Study}

The aim of this investigation is to evaluate the possibility of using selected invertebrate taxa as Completion Criteria for rehabilitation, using Iluka's Eneabba mineral sand mines and Worsley Alumina's Boddington bauxite mines as case studies. It has a series of specific objectives, namely:

- To standardize the methods of sampling invertebrates in order to evaluate the possibility of adopting invertebrates as complementary measures to existing Completion Criteria.

- To document the time taken to collect, sort and identify each taxonomic group in order to evaluate how economical it is to include them in rehabilitation monitoring schedules. 
- To evaluate the abundance of all 'orders', and the species composition and diversity of selected taxa (hemipterans (Worsley only), springtails, beetles, ants, spiders, 'myriapods' and isopod crustaceans), representing a range of functional groups, along a chronosequence of rehabilitation and in a series of unmined reference plots.

- To see how these invertebrate parameters vary across seasons and between years.

- To evaluate statistical methodologies for comparing invertebrate parameters in different ages and stages of rehabilitation with corresponding values in the controls.

- To relate the degree of invertebrate recolonisation to the degree of ecosystem recovery measured using other Completion Criteria.

\section{METHODOLOGY}

In addition to these two surveys, a questionnaire was sent to several environmental consulting companies who are known to conduct surveys of the biota of rehabilitated minesites. Respondents were asked to document the following for a range of representative surveys that they had carried out: the number of plots included in each survey (rehabilitation and controls), the taxa examined, the community and other parameters recorded, the time spent in the field monitoring or collecting material and the time spent in the laboratory processing the material and resulting data. All answers received were converted into mean number of hours needed for surveying and analysing one plot, so that the time spent in surveying different taxa and different parameters could be compared.

At both the Iluka and Worsley mines, a chronosequence of 10 rehabilitated areas and four unmined controls was selected. A $100 \mathrm{~m}$ invertebrate sampling transect (IST) was established in a representative area of each plot in such a way that edge-effects were avoided. Along each transect, 10 pitfall-traps were installed at $10 \mathrm{~m}$ intervals. Traps, $5 \mathrm{~cm}$ in diameter and containing preservative, were left open for 7 days, and then taken out for sorting. Each pitfall-trap position was used as the starting point for suction sampling in each IST. Invertebrates were vacuumed off the plants over a standardized period of time using a modified garden vacuum machine, and placed in containers of $70 \%$ alcohol for further sorting. Standardized quantities of litter were collected from each site for extraction of invertebrate material in Tullgren funnels. This sampling protocol represents a package designed to provide a relative estimation of the abundance and species richness of invertebrates on the ground (pitfall-traps), in the litter (Tullgren funnels) and on the herbs, shrubs and small trees (suction samples).

Invertebrate samples were sorted in the laboratory to broad taxonomic (ordinal) levels. Selected taxa were then sorted to species or, if names were not available, to morphospecies. Although of immense ecological importance, termites were not selected because they require a completely different sampling protocol to adequately census the species present in an area. The entire procedure, including sampling, was timed, and the period of time allocated to sampling, ordinal level sorting, the sorting of each individual taxonomic group and data processing were recorded.

Graphs of the abundance, species richness and diversity of each taxonomic group along the chronosequence and in the controls were first prepared. Then, data-sets were analysed using the PATN computer package (Belbin, 1995). The Hierarchical Cluster Analysis (UPGMA) was used to expose patterns of species composition in the data matrices of each taxon. The association measure Two Step (Belbin, 1980) was used to determine the quantitative relationship between each pair of species, and the Czekanowski (1932) measure was used to compare the plots according to their species similarities. An ordination of the plots for each taxon was created using results from these analyses. Cross-taxon analysis involved the estimation of the influence of each taxon on the overall community composition (McKenzie et al., 2000). For Iluka, data-bases of all taxa were used as sub-sets and were combined in order to create the community matrix. By contrast, a full set of floristic (species presence/absence), structural (plant density in each $25 \mathrm{~cm}$ layer of vegetation) and soil chemical (texture, moisture, macronutrients, conductivity and $\mathrm{pH}$ ) data were collected at Worsley and used for the community matrix. Using Pearson Product-Moment Correlation, the relationship between each pair of taxa was calculated. By doing this it was possible to derive similarity matrices for each data sub-set, as well as for the community data-set. These matrices were output as linear similarity vectors. This correlation matrix was converted to a dissimilarity matrix and Semi-strong Hybrid Scaling was used to 
reduce dimensionality of this matrix, so that relationships between different taxa data-sets could be displayed in three dimensions. Here, the Minimum Spanning Tree was superimposed to indicate the nearest-neighbour linkages in the ordination space. In order to provide some extrinsic measure of distance across the ordination space, 1000 uniform random matrices were generated and plotted in the same ordination space. The resulting diagram provided a measure of how much each taxon reflected the composition of another taxonomic group, and also of the congruence of each taxonomic group to the community matrix, which itself is our best estimate of the overall community composition.

\section{$4 \quad$ RESULTS}

Consulting companies spent between 1.8 and 57.6 hours per plot in the field (Table 1). The time varied greatly because of differences in taxa examined; the time required for surveying only plants ranged from 1.8 to $3.4 \mathrm{~h}$ and was considerably less than the time required for animal taxa ( $4.8 \mathrm{~h}$ for birds only and from 34.1 to $57.6 \mathrm{~h}$ for combined animal or plant and animal taxa). The time required to further process data varied between 1.4 and 31.2 hours per plot (from 1.4 to $9.4 \mathrm{~h}$ for plant data, $2.4 \mathrm{~h}$ for birds only and from 15.1 to 31.2 for combined taxa). These differences were not only due to differences in taxa examined, but also to the level the data were processed to. The ratio of the time spent in the field to the time spent in processing the data varied from between 1:0.3 to 1:3.2, and there were no trends in relation to the taxa examined.

Table 1 Analysis of the time taken to sample various taxa and to process the subsequent material (both standardized to hours per plot) during various flora and fauna studies conducted by environmental consultants. The ratio of field to laboratory time is also given

\begin{tabular}{|l|c|c|c|}
\hline Taxa (Consultant) & Mean - Field Time & Mean - Lab Time & Ratio \\
\hline & (hours per plot) & (hours per plot) & field:lab time \\
\hline Plants (A) & 1.8 & 2.4 & $1: 1.6$ \\
\hline Plants (B) & 3.4 & 1.4 & $1: 0.4$ \\
\hline Plants (C) & 2.9 & 9.4 & $1: 3.2$ \\
\hline Vertebrates+Ants (C) & 38.4 & 28.8 & $1: 0.7$ \\
\hline Plants+Vertebrates+Ants (D) & 34.1 & 31.2 & $1: 0.9$ \\
\hline Reptiles+Frogs (E) & 45.1 & 15.1 & $1: 0.3$ \\
\hline Reptiles+Frogs+Mammals (E) & 57.6 & 24 & $1: 0.4$ \\
\hline Birds (E) & 4.8 & 2.4 & $1: 0.5$ \\
\hline
\end{tabular}

The times taken to conduct the various invertebrate components of the Eneabba invertebrate survey, as well as to sort and tabulate the material, are shown in Table 2a. The mean time required to sample the entire invertebrate material at Eneabba was $2.3 \mathrm{~h}$ per plot, comprising: $1.1 \mathrm{~h}$ for pitfall traps, $1 \mathrm{~h}$ for suction samples and $0.2 \mathrm{~h}$ for litter samples. The time needed to identify material to ordinal level was in total $3.5 \mathrm{~h}$ per plot, comprising: $2.5 \mathrm{~h}$ for pitfall traps, $0.4 \mathrm{~h}$ for suction samples and $0.6 \mathrm{~h}$ for litter samples. The ratio of time spent in collecting material to time spent in the laboratory identifying and tabulating material to ordinal level was, on average, 1:1.5. The highest ratio was for litter samples (1:3), since much of the material was microscopic. The ratio for pitfall traps was 1:2.3 but, because relatively few animals were obtained in suction samples, the time spent in the laboratory processing this material was less than the time in the field (1:0.4). The equivalent data are also shown for Worsley (Table $2 b$ ) and, although they differ in detail, portray essentially the same trends. 
Table 2a also shows the number of species of plants, selected invertebrates and vertebrates obtained in the Iluka survey. It also shows the mean field time taken to sample and sort/identify these taxa from a plot. Although the most diverse group was the plants, beetles, spiders and ants were almost as rich in species. Birds and springtails were reasonably diverse, but 'myriapods', isopods, reptiles, amphibians and mammals were represented by few species. These trends were also reflected in the Worsley data (Table 2b) although, here, hemipterans were even more diverse than the plants.

Table 2 Numbers of species or orders sampled during five seasons in 10 rehabilitated plots and four heathland control plots at (a) the lluka mineral sand mine, Eneabba and (b) the Worsley Alumina bauxite mine. Also shown is the mean time to sort/identify each group to morphospecies or species level

\begin{tabular}{|c|c|c|c|c|c|c|}
\hline \multicolumn{7}{|l|}{ (a) } \\
\hline Taxon & \multirow{3}{*}{$\begin{array}{c}\text { Total } \\
\text { species } \\
\text { number } \\
\end{array}$} & \multirow{3}{*}{\begin{tabular}{|c|} 
Mean \\
species \\
for plot \\
\end{tabular}} & \multirow{3}{*}{$\begin{array}{c}\text { Time to } \\
\text { sample } \\
\text { one plot (hr) } \\
\end{array}$} & \multirow{3}{*}{\begin{tabular}{|c|} 
Time to sort \\
one plot \\
to species (hr)
\end{tabular}} & \multirow{3}{*}{$\begin{array}{l}\text { Total } \\
\text { time } \\
\text { (hr) } \\
\end{array}$} & \multirow{3}{*}{$\begin{array}{c}\text { Number of } \\
\text { species } \\
\text { per hr } \\
\end{array}$} \\
\hline & & & & & & \\
\hline & & & & & & \\
\hline Plants & 194 & 47.10 & 0.30 & 2.40 & 5.40 & 8.72 \\
\hline Birds & 47 & 20.38 & 4.00 & 0.00 & 4.00 & 5.10 \\
\hline Beetles* & 172 & 37.30 & 2.60 & 6.10 & 12.50 & 2.98 \\
\hline Ants* & 86 & 26.85 & 2.60 & 7.10 & 13.50 & 1.98 \\
\hline Spiders* & 95 & 16.60 & 2.60 & 4.90 & 11.30 & 1.47 \\
\hline Springtails* & 22 & 7.00 & 2.60 & 10.00 & 16.40 & 0.43 \\
\hline Vertebrates & 9 & 8.88 & 21.00 & 4.50 & 25.50 & 0.39 \\
\hline Myriapods* & 3 & 0.85 & 2.30 & 0.20 & 2.50 & 0.34 \\
\hline Isopods* & 3 & 0.71 & 2.30 & 0.20 & 2.50 & 0.28 \\
\hline \multicolumn{7}{|l|}{ (b) } \\
\hline \multirow[t]{3}{*}{ Taxon } & \multirow{3}{*}{\begin{tabular}{|c|} 
Total \\
species \\
number \\
\end{tabular}} & \multirow{3}{*}{\begin{tabular}{|c|} 
Mean \\
species \\
for plot \\
\end{tabular}} & \multirow{3}{*}{\begin{tabular}{|c|} 
Time to \\
sample \\
one plot (hr) \\
\end{tabular}} & \multirow{3}{*}{\begin{tabular}{|c|} 
Time to sort \\
one plot \\
to species (hr) \\
\end{tabular}} & \multirow{3}{*}{$\begin{array}{l}\text { Total } \\
\text { time } \\
\text { (hr) }\end{array}$} & \multirow{3}{*}{$\begin{array}{c}\text { Number of } \\
\text { species } \\
\text { per hr } \\
\end{array}$} \\
\hline & & & & & & \\
\hline & & & & & & \\
\hline Hemiptera* & 149 & 38.20 & 4.30 & 3.20 & 10.40 & 3.67 \\
\hline Beetles* & 237 & 52.10 & 4.30 & 8.40 & 15.60 & 3.34 \\
\hline Plants & 247 & 55.60 & 8.00 & 10.00 & 18.00 & 3.10 \\
\hline Spiders* & 182 & 30.20 & 4.30 & 2.90 & 10.10 & 2.99 \\
\hline Ants* & 182 & 38.00 & 4.30 & 5.70 & 12.90 & 2.94 \\
\hline Birds & 55 & 24.20 & 10.00 & 0.00 & 10.00 & 2.42 \\
\hline Springtails* & 20 & 14.60 & 4.30 & 9.50 & 16.70 & 0.87 \\
\hline Isopods* & 10 & 3.10 & 4.30 & 0.08 & 7.28 & 0.43 \\
\hline Vertebrates & 29 & 9.10 & 21.00 & 0.00 & 21.00 & 0.43 \\
\hline Myriapods* & 7 & 2.10 & 4.30 & 0.06 & 7.26 & 0.29 \\
\hline
\end{tabular}

* times to sort invertebrate groups assumes that they have already been sorted to order 
The time required to sample, process and identify plants, birds and most invertebrate groups was reasonable similar, both at Iluka and Worsley. In both cases, however, terrestrial vertebrate surveys required considerably more time. When the data were expressed as number of species per hour, the taxa fell into three groups. Plants, birds, beetles, ants, hemipterans (Worsley only) and spiders were time-effective, while terrestrial vertebrates, 'myriapods' and isopods yielded very low returns; springtails fell between these two groupings due to their intermediate species richness level and the time required to identify such small animals.

The data-yield in terms of numbers of species sampled per unit effort is of importance, because diverse samples are likely to yield more information about restoration success than less diverse taxa; taxa with low numbers of species can produce spurious results. This is well illustrated by the chronosequence data in Figure 2, which indicates that although a discernable trend is evident for a species-rich group such as the springtails (Collembola), it is impossible to detect any consistent trends with a group where few species were found, such as the slaters (Isopoda).
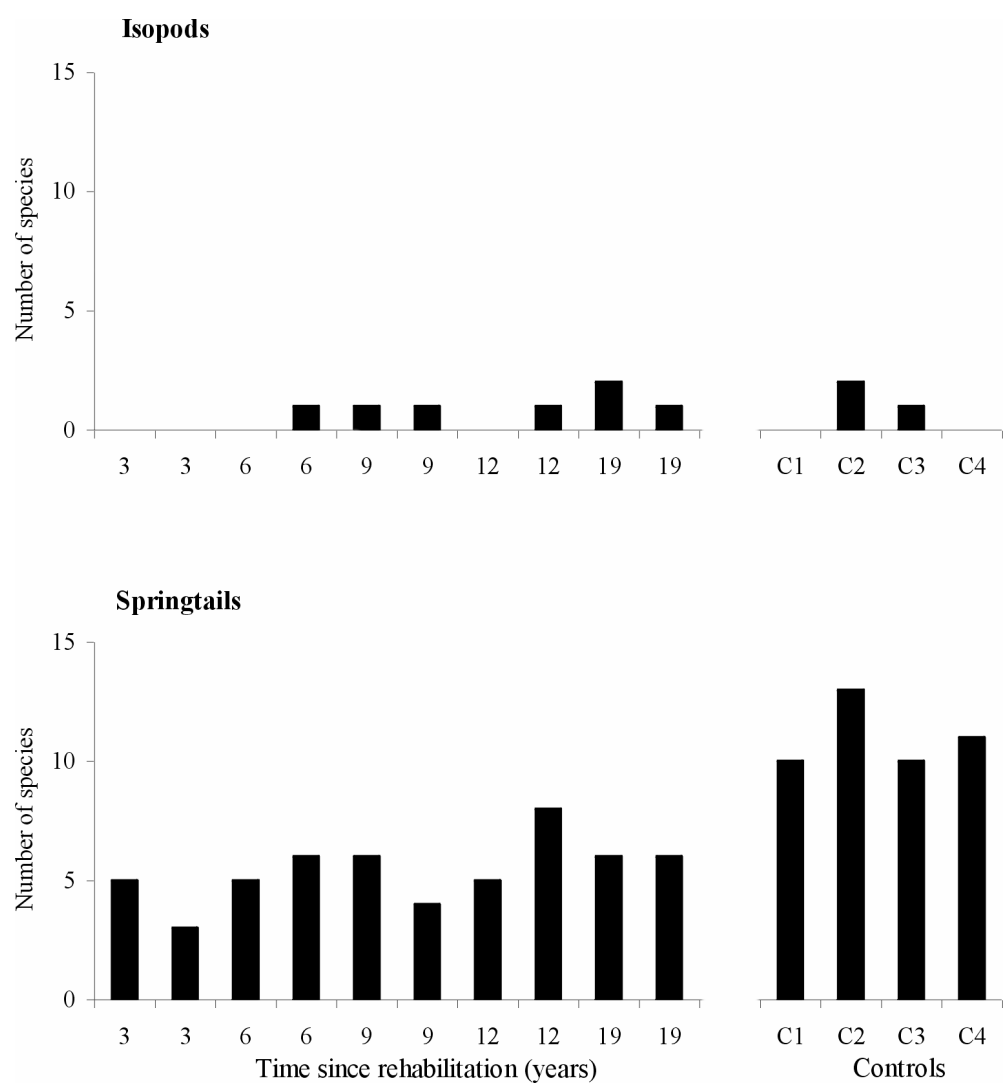

Figure 2 Comparisons between species richness of isopods and springtails on rehabilitated lluka sand mine plots of different age with values in control plots

Relationships and correlation coefficients between examined taxa and "overall community composition" are shown in Figure $3 \mathrm{a}$ and $\mathrm{b}$ for Iluka and Worsley, respectively. In both cases, 'myriapods' and isopods were excluded from the analysis, as they were not sufficiently numerous.

At Iluka (Figure 3a), plants, ants and beetles were the taxa with the highest correlation with the overall community composition. Terrestrial vertebrates (amphibians, reptiles and mammals), although not represented by a very high number of species, proved to be relatively close to the overall community composition, with a high correlation coefficient. For birds and spiders, the closest neighbour in ordination space was not overall community; birds showed highest correlation to springtails, and spiders to ants. This suggests that, despite high numbers of species in these taxa, they do not appear to be reliable indicators of the community in which they occur. Alternatively, their pattern of occurrence across the plots may be different from that of some of the other taxa that we considered. 
The results for Worsley are not quite equivalent, as plants were used as part of the community data-set. The fact that they contribute so heavily to the variance in this data-set meant that there was no point in relating them to the overall community. Spiders, beetles and hemipterans were most closely correlated with the community data-set, followed by ants and terrestrial invertebrates. As with Iluka, springtails and birds exhibited relatively low correlations with the community data-set (Figure 3b, Table 3).

The degree to which the assemblages of each taxonomic group represents the assemblages of the other taxa is also of interest, as it provides an indication of how effective each group might be in acting as a surrogate for the general composition of the biota. The last two rows of Table 3 show the mean correlations for each taxon for both Worsley and Iluka. In both cases, ants provide the best indication of the variability in other taxa, beetles are reasonable, and birds are consistently poor indicators. Hemipterans were also good indicators at Worsley, although comparable data do not exist for Iluka. The two areas differed in that springtails and vertebrates were good indicators at Iluka, and spiders were good indicators at Worsley; terrestrial vertebrates were the poorest surrogate indicators at Worsley.

(a)

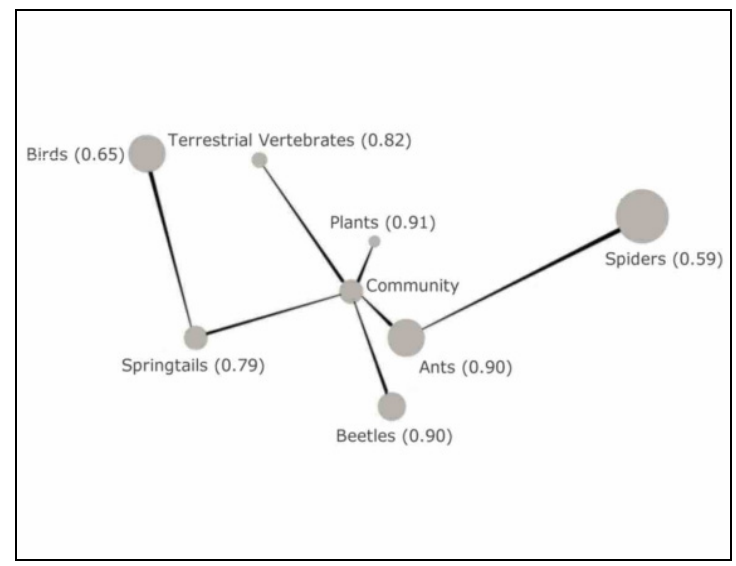

(b)

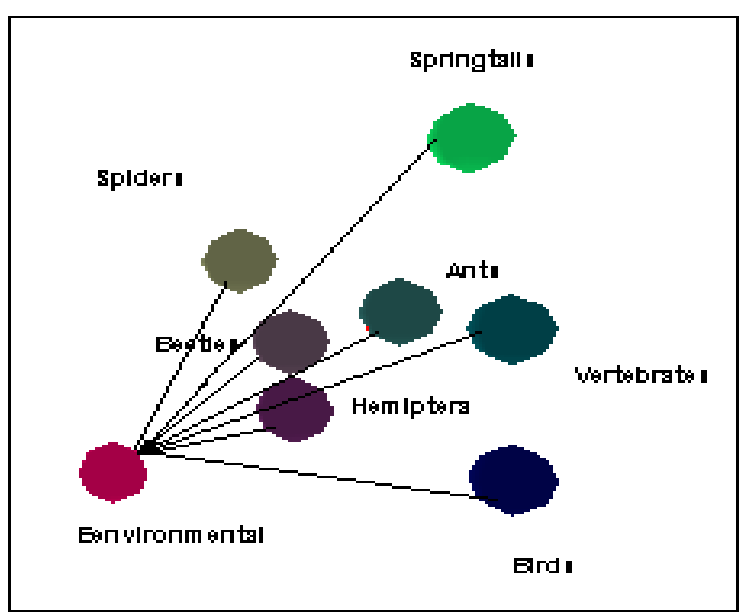

Figure 3 Comparison of the community patterns derived from seven taxa sub-sets, and from the total data-set for (a) the lluka sand mine and (b) the Worsley Alumina bauxite mine. A matrix of correlation coefficients was compiled from a pairwise comparison of the relevant transect similarity matrices. Results are displayed in three-dimensions using Semi-strong Hybrid Scaling. Minimum Spanning Tree linkages are superimposed to indicate nearest neighbours in community space. The correlations of each taxon with the community are shown in brackets 


\begin{abstract}
Pearson coefficient values between the association matrices derived from each of the 10 Worsley data-sets (the seven taxonomic sub-sets, plants, soil chemistry and all the environmental variables combined) for the 10 rehabilitated and the four control plots. The first mean value at the bottom of the table is the mean correlation between the taxon with each other group of the biota; the second mean value shows the equivalent figures for lluka
\end{abstract}

\begin{tabular}{|c|c|c|c|c|c|c|c|c|c|}
\hline & Spiders & & & & & & & & \\
\hline Springtails & 0.52 & Springtails & & & & & & & \\
\hline Hemiptera & 0.75 & 0.49 & Hemiptera & & & & & & \\
\hline Ants & 0.64 & 0.73 & 0.76 & Ants & & & & & \\
\hline Beetles & 0.70 & 0.53 & 0.79 & 0.73 & Beetles & & & & \\
\hline Vertebrates & 0.66 & 0.34 & 0.65 & 0.65 & 0.56 & Vertebrates & & & \\
\hline Birds & 0.49 & 0.82 & 0.54 & 0.74 & 0.62 & 0.35 & Birds & & \\
\hline Plants & 0.61 & 0.18 & 0.58 & 0.38 & 0.48 & 0.39 & 0.15 & Plants & \\
\hline Soil Chem & 0.48 & 0.11 & 0.47 & 0.29 & 0.27 & 0.24 & 0.03 & 0.41 & Soil Chem \\
\hline Comb. Env & 0.61 & 0.17 & 0.58 & 0.38 & 0.48 & 0.39 & 0.15 & 1.00 & 0.42 \\
\hline Mean & 0.63 & 0.57 & 0.67 & 0.71 & 0.66 & 0.54 & 0.59 & $\mathrm{nt}$ & $\mathrm{nt}$ \\
\hline Mean & 0.49 & 0.66 & nd & 0.69 & 0.61 & 0.64 & 0.57 & $\mathrm{nt}$ & \\
\hline
\end{tabular}

\title{
5 DISCUSSION
}

The results of this survey indicate that collection of invertebrate material can be undertaken as rapidly as that for plants, and much more rapidly than for terrstrial vertebrate material. The time to process invertebrate material is in the same order as for plants, although it is longer than the time taken to process vertebrate data. The reason for this is probably that once vertebrates are observed and recorded in the field, there is little to do. Nevertheless, the cumulative time taken to obtain and process invertebrate material is much less than for terrestrial vertebrates. The information yield for certain groups of invertebrates, in terms of number of species per plot, is in the same range as for plants and is considerably higher than for amphibians, reptiles and mammals. If additional groups of invertebrates had been sorted to species level, the information content of the invertebrate samples would be even higher.

This high invertebrate diversity has implications for the types of statistical analyses that may be performed on the data. Collections that contain high numbers of species lend themselves to robust data analyses by such techniques as classification, ordination and other multivariate analyses. Trends in diversity indices also tend to be more meaningful in cases where high numbers of species are involved; variations in low-diversity taxa between sites can yield serendipitous results.

There is also the issue of how well each taxon represents differences, or changes, in community composition between plots. There are differences between the two studies, although in both studies ants are considered to be amongst the best indicators of the community, and birds amongst the poorest.

The invertebrate data reported on here prove themselves to be cost-effective to gather and potentially high in information content. Being the most diverse members of the animal kingdom, their inclusion in surveys can contribute to data on physical factors and plant and vertebrate communities in habitats. As well as strengthening the conclusions reached from a study of these aspects alone, invertebrate data can provide an indication of the degree of re-establishment of ecosystem functioning.

Despite the efficiency in yielding data, inclusion of invertebrates in Completion Criteria does represent a measurable time and cost commitment. In cases where a company has several areas of rehabilitation to assess, it is recommended that surveys be performed in a representative sub-set of these areas, and that the results be applied to the remaining unsurveyed areas.

\section{CONCLUSIONS}

This review has indicated that invertebrates, being the most diverse members of the animal kingdom can, at least, contribute to the data on physical factors and plant and vertebrate communities in rehabilitated areas. 
As well as strengthening the conclusions reached from a study of these aspects alone, invertebrate data can provide an indication of the degree of re-establishment of ecosystem functioning. Should Completion Criteria become widely adopted in the mining or any other industry, information such as this would prove invaluable in the development of such indicators. When the processes of invertebrate recolonisation are sufficiently well understood, they will provide a valuable addition to the more widely accepted physical and biological measures that are currently being discussed (Tacey and Treloar, 1994).

\section{ACKNOWLEDGEMENTS}

The authors wish to thank Iluka Resources Ltd (formerly RGC Mineral Sands Ltd) and Worsley Alumina Pty Ltd for funding this project. We also wish to thank Mattiske Consulting Pty Ltd, Ninox Wildlife Consulting and Halpern Glick Maunsell Pty Ltd for participating in this survey. Special thanks to Norm McKenzie from CALM for his help with the ordination and cross-taxon congruence analysis.

\section{REFERENCES}

Abbott, I. (1989) The influence of fauna on soil structure. In Animals in Primary Succession: The Role of Fauna in Reclaimed Lands. Ed. J. D. Majer. Cambridge University Press, Cambridge, pp. 39-50.

Belbin, L. (1980) TWOSTEP: a program incorporating asymmetric comparisons that uses two steps to produce a dissimilarity matrix. CSIRO Division of Land Use Research Technical Memorandum 80/9. CSIRO, Canberra.

Belbin, L. (1995) PATN Technical Reference. CSIRO Division of Wildlife and Ecology, Canberra.

Czekanowski, J. (1932) Coefficient of racial likeness, und durchschnittliche differenz. Anthropologischer Anzeiger 9: 227-249.

EPA (2006) Guidance for the Assessment of Environmental Factors. Draft Guidance Statement No. 6. Rehabilitation of Terrestrial Ecosystems. Environmental Protection Authority of Western Australia, Perth.

Erwin, T.L. (1991) How many species are there? Revisited. Conservation Biology 5, pp. 330-333.

Faegri, K. and van der Pijl, L. (1971) The Principles of Pollination Ecology. Pergamon Press, London.

Hutson, B.R. (1989) The role of fauna in nutrient turnover. In Animals in Primary Succession: The Role of Fauna in Reclaimed Lands. Ed. J. D. Majer. Cambridge University Press, Cambridge, pp. 51-70.

Majer, J.D. (1989) Fauna studies and land reclamation technology - a review of the history and need for such studies. In Animals in Primary Succession: The Role of Fauna in Reclaimed Lands. Ed. J. D. Majer. Cambridge University Press, Cambridge, pp. 5-33.

Majer, J.D. (1990) Rehabilitation of disturbed land: Long term prospects for the recolonization of fauna. Proceedings of the Ecological Society of Australia 16, pp. 509-519.

McKenzie, N.L., Keighery, GJ., Gibson, N. and Rolfe, J.K. (2000) Patterns in the biodiversity of terrestrial environments in the southern Carnarvon Basin, Western Australia. Records of the Western Australian Museum Supplement No. 61, pp. 511-546.

Mills, C., Chandler, R. and Caporn, N. (1992) Completion Criteria. Proceedings of Conference on Management and Rehabilitation of Mined Lands. Curtin University of Technology, Perth.

Tacey, W. and Treloar, J. (1994) What do we want Completion Criteria to achieve? Proceedings of the 19th Australian Mining Industry Council Environmental Workshop. AMIC, Canberra, pp. 246-256.

Waggitt, O.W. and McQuade, C.V. (1994) Mine close-out Criteria - Present guidelines and future trends in Australia. Proceedings of the AusIMM Annual Conference, Darwin, pp. 407-410.

Ward, S.C., Majer, J.D. and O’Connell, A.M. (1991) Decomposition of eucalypt litter on rehabilitated bauxite mines. Australian Journal of Ecology 6, pp. 251-257.

Whelan, R.J. and Main, A.R. (1979) Insect grazing and post-fire succession in south-west Australian woodland. Australian Journal of Ecology 4, pp. 387-398.

Wilson, E.O. (1987) The little things that run the world (the importance and conservation of invertebrates). Conservation Biology 1, pp. 344-346. 